\title{
Endocrine resistance in
}

\section{hormone-responsive breast cancer: mechanisms and therapeutic strategies}

\author{
Conleth G Murphy1,2 and Maura N Dickler 3,4 \\ ${ }^{1}$ Bons Secours Hospital Cork, Medical Oncology, Cork, Ireland \\ 2University College Cork, Medicine, Cork, Ireland \\ ${ }^{3}$ Memorial Sloan-Kettering Cancer Center, Breast Medicine Service, New York, New York, USA \\ 4Joan and Sanford I Weill Medical College of Cornell University, Medicine, New York, New York, USA
}

Correspondence

should be addressed

to $\mathrm{M}$ N Dickler

Email

dicklerm@mskcc.org

\begin{abstract}
The majority of breast cancers may be considered hormone responsive due to expression of hormone receptors $(\mathrm{HR}+)$. Although endocrine therapy is always considered for advanced $\mathrm{HR}+$ breast cancer, the emergence of resistance is inevitable over time and is present from the start in a proportion of patients. In this review, we explore the mechanisms underlying de novo and acquired resistance to endocrine therapy. We comprehensively review newly approved and emerging therapies that have been developed to counteract specific mechanisms of resistance. We discuss the challenges pertinent to this therapeutic arena including the potential relief of negative regulatory feedback inhibition with compensatory pathway activation and the evolution of molecular changes in $\mathrm{HR}+$ breast cancers during treatment. We discuss strategies to address these challenges in order to develop rational therapy approaches for patients with advanced HR+ breast cancer.
\end{abstract}

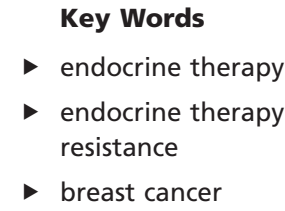

Endocrine-Related Cancer (2016) 23, R337-R352

\section{Introduction}

Approximately $70 \%$ of advanced breast cancers are considered 'hormone responsive' as defined by expression of the estrogen receptor (ER), progesterone receptor (PR), or both. Various thresholds have been proposed for the level of ER and/or PR immunohistochemical staining required to qualify a breast cancer as hormone responsive, but current guidelines from the American Society of Clinical Oncology (ASCO) and College of American Pathologists (CAP) recommend that these assays be considered positive if at least $1 \%$ of tumor nuclei stain for the marker in the setting of appropriate internal and external controls (Hammond et al. 2010). In reality, not all of these tumors with hormone receptor (HR) expression are truly sensitive to manipulation of the ER pathway, with approximately $20 \%$ of HR+ metastatic breast cancers
(MBC) proving refractory to first-line endocrine therapy (McGuire et al. 1977). Furthermore, the emergence of resistance to endocrine manipulation is inevitable with advanced breast cancer. Although clinicians are encouraged to consider second- and third-line endocrine therapies for patients who initially benefited from firstline treatment (NCCN 2016), the clinical benefit rate declines from approximately 70\% for first-line fulvestrant or aromatase inhibitors to around 30\% for second or greater lines of therapy (Chia et al. 2008, Ellis et al. 2015). Yet, endocrine therapy can be well tolerated, with durations of response extending into years in some cases. The challenge therefore is to improve our understanding of the mechanisms of endocrine resistance and to develop treatment strategies that utilize this understanding to

Published by Bioscientifica Ltd 
extend the duration of effective therapy while minimizing toxicity. In this review, we will discuss the principle mechanisms of endocrine resistance in $\mathrm{HR}+$ breast cancer. We will highlight emerging treatments that have been developed to overcome specific resistance mechanisms and review the results of recently reported studies with these agents. Table 1 summarizes currently enrolling and recently completed phase II/III studies whose results will inform the future selection of therapies for patients with HR+ breast cancer.

\section{Mechanisms of resistance: ESR1 mutations}

Although loss of ER expression would appear to be a reasonable explanation for the emergence of endocrine resistance, studies of paired primary and metastatic tumor samples indicate that this occurs in only $10 \%$ of cases (Sighoko et al. 2014). Similarly, Ellis et al. (2008) found loss of ER expression during neoadjuvant endocrine therapy in less than $10 \%$ of patients, and notably in fewer than $20 \%$ of non-responders, who would be expected to represent an endocrine-resistant phenotype. Therefore, the estrogen receptor pathway remains a potential target in the majority of cases of endocrine resistance. If loss of ER expression is not the mechanism of resistance in these patients, then what is? We know from studies of patients developing resistance to other 'oncoreceptor'-targeted therapies such as tyrosine kinase inhibitors of EGFR and c-Kit that resistance is frequently driven by the emergence of additional mutations in the target oncogene (Pao et al. 2005, Tamborini et al. 2006). It is not so surprising, therefore, that a similar molecular mechanism might underpin resistance to therapies targeting the ER. Specifically, attention has recently focused on mutations in the gene ESR1, which encodes ER $\alpha$ (the ER expressed in breast cancer cells). Mutations in ESR1 appear to be rare in a treatment-naïve setting and indeed were not identified in a sequencing analysis conducted on 390 ER-positive primary breast cancers (Cancer Genome Atlas Network 2012). However, recent work has revealed that ESR1 mutations become more frequent in metastatic and pretreated ER+ breast cancers. Toy et al. (2013) detected mutations in nine of 36 patients with $\mathrm{MBC}$ progressing on endocrine therapy. Highly recurrent mutations were noted at two residues in the ligand-binding domain: replacing tyrosine at residue 537 with serine or asparagine (p.Tyr537Ser/Asn) and replacing aspartic acid at residue 538 with glycine (p.Asp538Gly). The two mutations at the Tyr537 residue had previously been described in studies of small numbers of patients with MBC (Zhang et al. 1997, Li et al. 2013). A schematic representation of the ESR 1 gene with the location of the mutations detected (confined to the LBD) is shown in Fig. 1. Sequencing was also performed on primary (untreated) and metastatic (post-aromatase inhibitor treatment) tumors of patients participating in the BOLERO-2 study, and ESR1 mutations were found in $5 / 44(11 \%)$ tumors in previously treated patients vs 6/183 (3\%) tumors in treatment-naïve patients. Robinson et al. (2013) found ESR1 mutations in 6/11 patients with metastatic ER+ breast cancer, all of whom had received antiestrogens and aromatase inhibitors (AIs). For three of these six patients, primary tumor samples were available for comparison and showed no evidence of ESR1 mutation. Taken together, these two studies indicate an ESR1 mutation rate in advanced hormone receptor-positive (HR+) breast cancer of approximately $22 \%$. Similarly, Jeselsohn and colleagues (2014) found a mutation rate of $12 \%$ among 76 patients with metastatic ER+ breast cancer, increasing to $20 \%$ in a subset with heavily pretreated disease. These mutations have clear therapeutic relevance, as functional analysis in both the Toy and Jeselsohn studies revealed relative resistance to tamoxifen and fulvestrant, which could be partially abrogated with increased dose. Analysis of ESR1 mutations has been performed on archival plasma samples of patients with $\mathrm{HR}+\mathrm{MBC}$ and prior nonsteroidal AI treatment participating in two large randomized phase II studies (Fribbens et al. 2016). These analyses indicated mutation rates of $25 \%$ among patients with progression on endocrine therapy in the PALOMA3 study (rising to $29 \%$ in patients with prior AI therapy) and 39\% among patients with prior AI sensitivity in the SoFEA study. The higher rate of mutations in the SoFEA population is in keeping with the existing evidence, indicating that ESR 1 mutations are a rare cause of primary endocrine resistance, but emerge more commonly with acquired secondary resistance to AI therapy.

\section{Mechanisms of resistance: growth factor receptors, $\mathrm{PI} 3 \mathrm{~K} / \mathrm{AKT} / \mathrm{mTOR}$ and RAF/MEK/ERK pathway activation}

Overexpression and/or amplification of growth factor receptors including FGFR1, HER2, HER3, EGFR, and IGF1R are associated with the emergence of endocrine resistance (Ellis et al. 2006, Frogne et al. 2009, Turner et al. 2010, Fox et al. 2011). These growth factor receptor pathways converge on the PI3K/AKT/mTOR and RAF/MEK/ERK pathways.

Published by Bioscientifica Ltd 


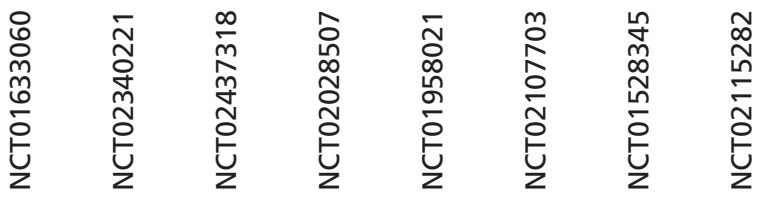

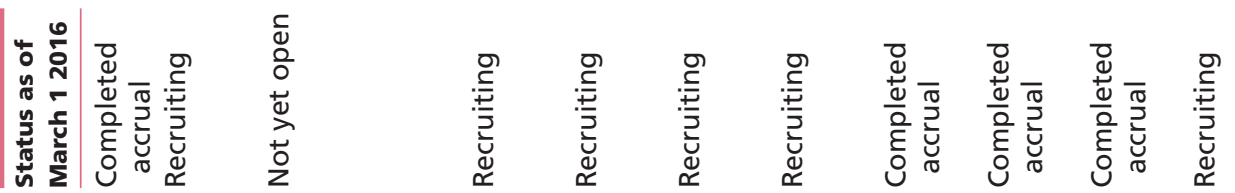

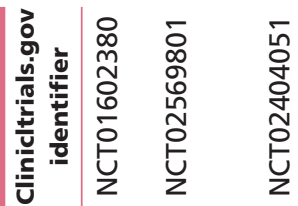

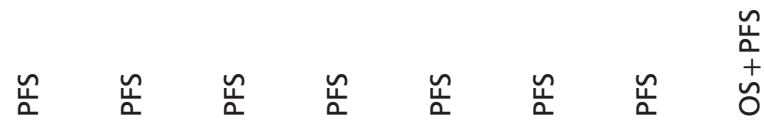
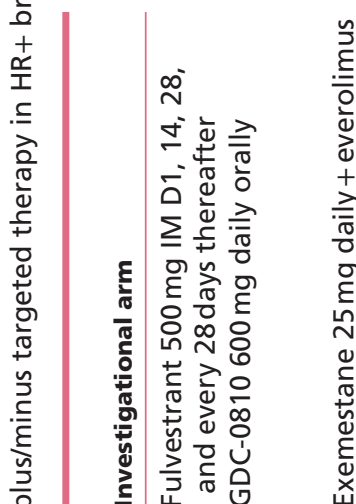

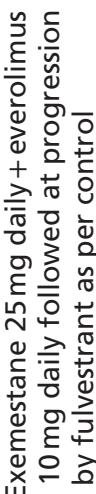

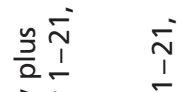

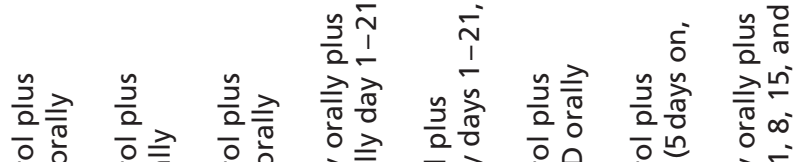

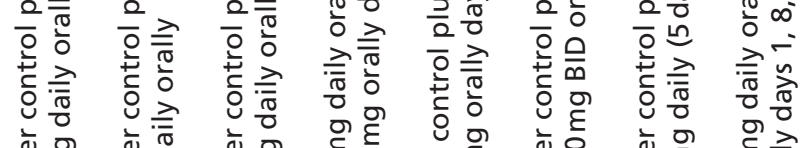

๘

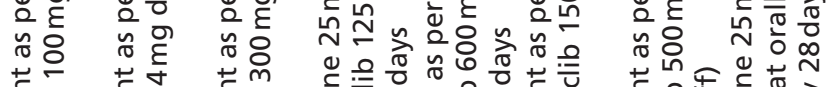

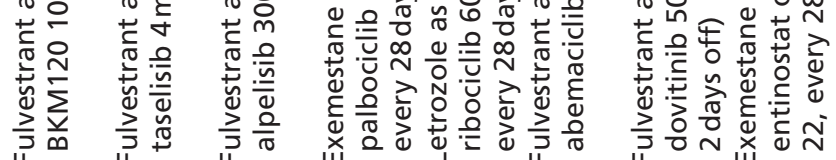

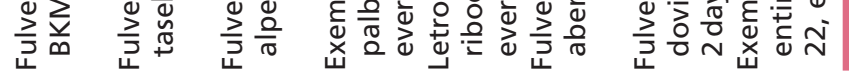

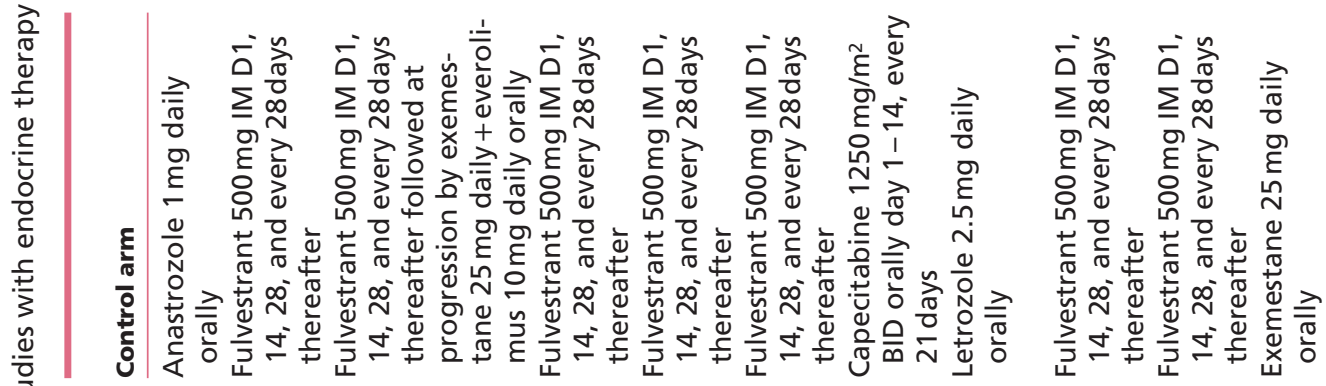

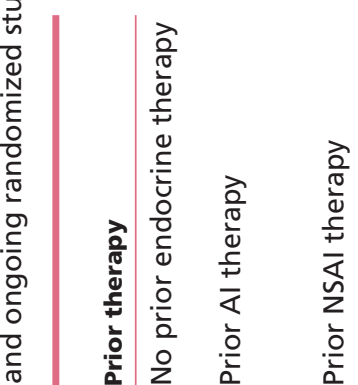

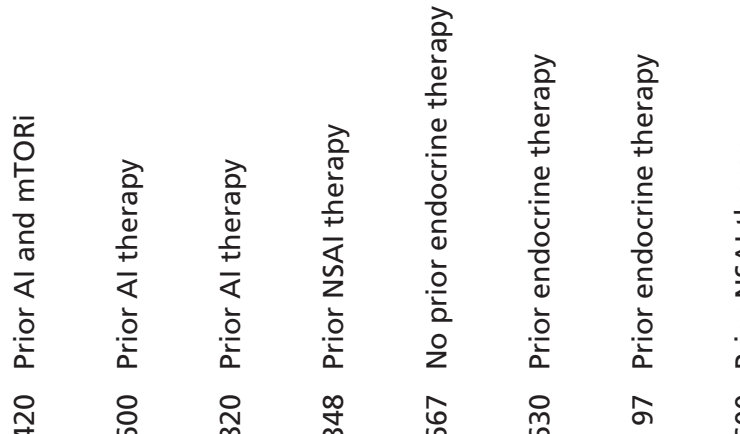

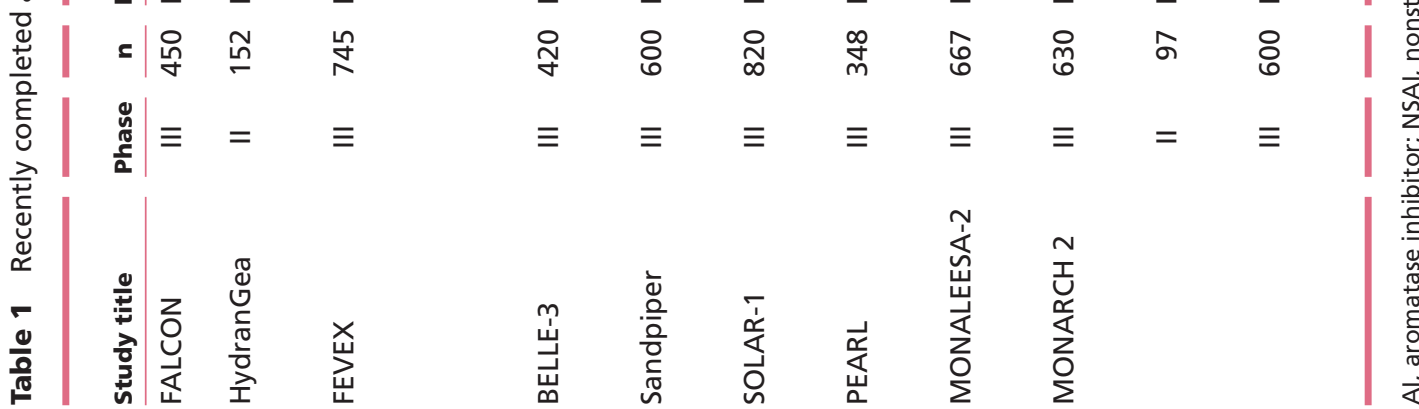




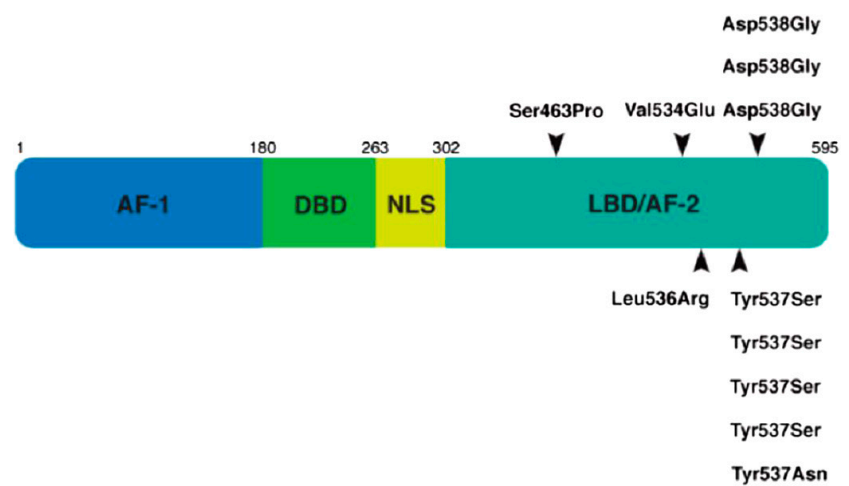

Figure 1

Diagram of ER domains with the location of mutations identified in tumor samples from 36 patients with pretreated ER+ breast cancer. AF-1: activation function-1; DBD: DNA binding domain; NLS: nuclear localizing signal; LBD: ligand binding domain; AF-2: activation function-2. Reproduced, with permission, from Toy W, Shen Y, Won H Green B, Sakr RA, Will M, Li Z, Gala K, Fanning S, King TA, et al. 2013 ESR1 ligand-binding domain mutations in hormone-resistant breast cancer. Nature Genetics 45 1439-1445.

The PI3K pathway is illustrated in Fig. 2. PI3K is a lipid kinase enzyme belonging to the phosphatidylinositide 3-kinase family (Raynaud et al. 2009). PI3K consists of a regulatory subunit and a catalytic (p110) subunit, which exists in four isoforms: $\mathrm{p} 110 \alpha, \beta, \gamma$, and $\delta$. The PIK3CA gene encodes the p110 $\alpha$ isoform and is mutated in up to $40 \%$ of human breast cancers (Campbell et al. 2004, Levine et al. 2005, Saal et al. 2005, Arthur et al. 2014). The frequency of PIK3CA mutations is not increased in metastatic compared with primary breast cancers and there is high concordance between matched primary and recurrent tumor samples for mutation status (Meric-Bernstam et al. 2014). Aberrations in the PI3K intracellular signaling pathway occur in approximately $70 \%$ of breast cancers, including the aforementioned PIK3CA mutations; mutation or amplification of other genes encoding isoforms of PI3K subunits; mutations of the downstream effectors AKT1, AKT2, and PDK1; and loss of inhibitory signals from lipid phosphatases PTEN and INPP4B (Fu et al. 2013). PI3K pathway hyperactivation promotes estrogen-independent ER transcriptional activation (Miller et al. 2011b). Conversely, PI3K inhibition results in increased estrogen dependence, providing a rationale for combined endocrine therapy and PI3K inhibition in endocrine-resistant breast cancer (Ghayad et al. 2008, Loi et al. 2010, Miller et al. 2010, Bosch et al. 2015). The mammalian target of rapamycin (mTOR) protein kinase complex is a key downstream effector of the PI3K/AKT pathway existing in two distinct multiprotein complexes, mTORC1 and mTORC2 (Lauring et al. 2013).

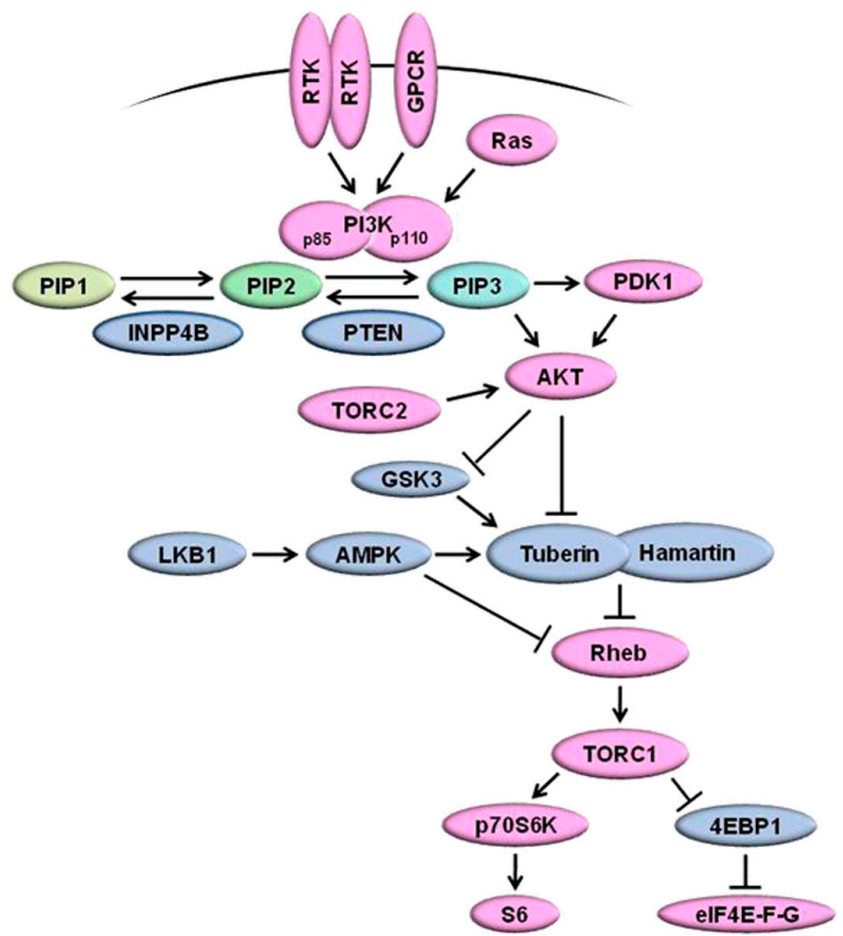

Figure 2

Diagram of the phosphatidylinositol 3-kinase signaling pathway. Tumor promoters and suppressors are labeled in pink and blue, respectively. AMPK, AMP-activated protein kinase; GPCR, G-protein-coupled receptor; GSK3, glycogen synthase kinase 3; INPP4B, inositol polyphosphate-4phosphatase, type II; LKB1, liver kinase B1; PDK1, phosphoinositidedependent kinase 1; PI3K, phosphatidylinositol 3-kinase; PIP1, phosphatidylinositol monophosphate; PIP2, phosphatidylinositol 4,5-bisphosphate; PIP3, phosphatidylinositol 3,4,5-trisphosphate; PTEN phosphatase and tensin homolog; RTK, receptor tyrosine kinase. Adapted, with permission, from Miller TW, Rexer BN, Garrett JT \& Arteaga CL 2011a Mutations in the phosphatidylinositol 3-kinase pathway: role in tumor progression and therapeutic implications in breast cancer. Breast Cancer Research 13224.

AKT phosphorylation leads to increased mTORC1 kinase activity, with resultant effects on protein synthesis and cellular metabolism.

\section{Mechanisms of resistance: cell cycle checkpoint alterations}

Dysregulated cell cycle progression via alterations of key cell cycle checkpoints can also contribute to loss of endocrine responsiveness (Murphy \& Dickler 2015). All cells (both normal and cancerous) receive a plethora of proliferative and antiproliferative signals, the balance of which determines whether a cell will progress from the G1 phase of the cell cycle into the $\mathrm{S}$ (synthesis) phase and commit to another cycle of cell division, or withdraw into the quiescent phase (Pardee 1989). Antiproliferative

Published by Bioscientifica Ltd. 
signals are communicated through the retinoblastoma tumor suppressor protein (pRb) as well as p107 and $\mathrm{p} 130$. Rb itself is regulated by complexes of cyclin and cyclin-dependent kinases (CDKs), a family of serinethreonine protein kinases (Morgan 1997). Progression through the G1-S phase requires phosphorylation of Rb by the cyclin-dependent kinase CDK4 (or the highly homologous enzyme CDK6) in complex with cyclin D1, D2, or D3 (Sherr 1995). Hyperphosphorylation of $\mathrm{Rb}$ reduces its ability to repress activity of the E2F family of transcription factors, leading to increased synthesis of genes whose products are essential for DNA replication and resultant progression to $S$ phase, DNA replication, and mitotic progression (Weinberg 1995). Many tumors increase cyclin D-dependent activity and thereby escape senescence via multiple mechanisms such as p16 inactivation, CDK4 amplification, CDK4 mutation with loss of INK4 binding, cyclin D1 translocation, amplification, or overexpression (Shapiro 2006). Preclinical models suggest a particular role for CDK4/6 inhibition in $\mathrm{ER}+$ breast cancer cells, including estrogen-sensitive and estrogen-resistant models. Cyclin D1 amplification is a common event in ER+ breast cancer, identified in 58\% of luminal B cancers and 29\% of luminal A cancers (Cancer Genome Atlas Network 2012). Antiestrogen-induced growth arrest in ER+ breast cancer cells is accompanied by decreased cyclin D1 expression, whereas the emergence of endocrine resistance is associated with persistent cyclin D1 expression and $\mathrm{Rb}$ phosphorylation (Watts et al. 1995, Thangavel et al. 2011). Evidence of a continued role for CDK4/6 inhibition in endocrine-resistant ER+ cells comes from the evaluation of the CDK4/6 inhibitor palbociclib in vitro in a panel of molecularly characterized breast cancer cell lines that demonstrated most activity in luminal cancers including those with conditioned estrogen resistance (Finn et al. 2009).

\section{Mechanisms of resistance: enhanced autophagy}

Macroautophagy (autophagy hereafter) is an intracellular process leading to the degradation of damaged or unnecessary subcellular organelles (Clarke et al. 2015). Along with endoplasmic reticulum stress and the unfolded stress response, autophagy represents a key mechanism by which cancer cells and normal cells deal with various stresses in their microenvironment. In normal cells, it acts at a low level in fed conditions but is up-regulated in the context of stresses such as starvation and hypoxia, whereas cancer cells demonstrate persistent high levels of basal autophagy (White 2012). Inhibition of autophagy has been linked to restoration of endocrine sensitivity and promotion of apoptotic cell death in preclinical models of endocrine-resistant breast cancer (Maycotte \& Thorburn 2014). It should be stressed that the pathways involved are complex and feature a high degree of redundancy, leading to differing effects of autophagy inhibition depending on tissue type and context.

\section{New and emerging therapies for HR+ breast cancer}

\section{SERDs}

The identification of mutations of ESR1 resulting in ligandindependent activation of $\mathrm{ER} \alpha$ has reignited interest in a group of agents that result in degradation of ER: the selective estrogen receptor down-regulators (SERDs). Fulvestrant is the first drug in this class and represented a welcome addition to the two other classes of approved breast cancer endocrine therapies (selective estrogen receptor modulators (SERMs) such as tamoxifen and the aromatase inhibitors (AIs) such as anastrozole, letrozole, and exemestane). In contrast to SERMs, SERDs act as ER antagonists without any tissue-specific agonist properties (Wakeling et al. 1991). Binding of fulvestrant to the ligand binding domain (LBD) of ER $\alpha$ results in a conformation incompatible with transcriptional activation (Pike et al. 2001). As noted above, fulvestrant is capable of binding to ER $\alpha$ in the setting of ESR1 LBD mutations, but higher doses are required to achieve target effects. Fulvestrant has a second important effect on $\mathrm{ER} \alpha$, targeting the receptor for proteasomal degradation, leading to its designation as the first-in-class SERD member (Fawell et al. 1990). Importantly, the conformational transcriptional deactivation of $E R \alpha$ appears separate from the ER degrading effect, with the former appearing to be more important in terms of clinical effects (Wardell et al. 2011).

\section{Fulvestrant clinical studies}

Fulvestrant was compared with the nonsteroidal aromatase inhibitor anastrozole in the second-line therapy of women with $\mathrm{HR}+$ advanced breast cancer in two phase III studies (Howell et al. 2002, Osborne et al. 2002). The dose of fulvestrant used in these studies was $250 \mathrm{mg}$ by intramuscular (IM) injection on day 1 , 15,29 , and every 28 days thereafter. Combined analysis (Robertson et al. 2003) indicated non-inferiority of fulvestrant in terms of the primary endpoint of time to progression (TTP). The SoFEA study compared fulvestrant (with or without anastrozole) with the steroidal AI

Published by Bioscientifica Ltd. 
exemestane in patients with $\mathrm{HR}+\mathrm{MBC}$ and evidence of prior endocrine sensitivity in either the adjuvant or advanced setting (Johnston et al. 2013). No difference in the primary endpoint of progression-free survival (PFS) was seen between the three arms. Subsequent prospective-retrospective analysis of ESR1 mutation status in archival plasma circulating tumor DNA (ctDNA) indicated improved outcomes with fulvestrant compared with exemestane among patients with ESR1 mutations, whereas no difference was seen in patients who were ESR1 wild type (Fribbens et al. 2016). These results indicate a potential role for ESR1 mutation status in selecting endocrine therapy in patients with $\mathrm{HR}+\mathrm{MBC}$, ideally with re-evaluation of mutation status at any new 'decision point' in the sequence of endocrine therapies.

The phase III CONFIRM study has shown that a higher dose of fulvestrant is superior to the dose utilized in the initial clinical studies, for both diseasefree survival (DFS) and overall survival (OS) (Di Leo et al. 2010, Di Leo et al. 2014). The dose revealed to be superior in CONFIRM is $500 \mathrm{mg}$ (or two $250 \mathrm{mg}$ IM injections, one into each buttock) on days 1, 15, 29, and every 28 days thereafter. The open-label randomized phase II FIRST study evaluated this higher $500 \mathrm{mg}$ dose of fulvestrant vs anastrozole in the first-line therapy of ER+ advanced breast cancer. This was a non-inferiority study with a primary endpoint of clinical benefit rate (CBR). It met this endpoint with a CBR of $72.5 \%$ vs $67 \%$, respectively, for fulvestrant and anastrozole (Robertson et al. 2009). Subsequent unplanned analyses demonstrated a striking improvement in TTP with fulvestrant (23.4 vs 13.1 months, HR 0.66, $P=.01$ ) as well as an improvement in OS (Robertson et al. 2012). It should be stressed that this OS analysis comes from a small phase II study and was not planned in the original protocol; nevertheless, it has certainly sparked interest for the outcome of the large double-blind phase III FALCON study (https://www.clinicaltrials.gov/ct2/ show/NCT01602380, accessed on 10th January 2016), which has already completed accrual.

The major downside to this agent has been its poor oral bioavailability, requiring intramuscular administration. Furthermore, the degree of ER degradation achieved with fulvestrant appears suboptimal: paired biopsy data indicate that therapy at the initially approved $250 \mathrm{mg}$ dose results in reduction of ER $\alpha$ levels to $50 \%$ of baseline, rather than to undetectable levels (Robertson et al. 2001). Even at the higher dose of $500 \mathrm{mg}$, serial [(18)F] fluoroestradiol PET scans reveal incomplete suppression of estrogen uptake in 38\% of patients (van Kruchten et al. 2015). Taken together, these factors indicate a need to develop next-generation SERDs that would not only be orally bioavailable for patient convenience but also exhibit more efficient receptor degradation.

\section{Newer SERDs}

The recognition that $\mathrm{ER} \alpha$ remains a viable target even in the setting of endocrine resistance and the limitations of fulvestrant led to the search for a new generation of orally bioavailable highly selective SERDs. GDC0810 is one such agent developed through a process of conformation based profiling, followed by refinement and modification (McDonnell et al. 2015). GDC-0810 demonstrated good oral bioavailability and was active in models of tamoxifen-sensitive and tamoxifenresistant breast cancer (Lai et al. 2015). The phase I component of a phase I/IIa first-in-human study was presented at the American Association for Cancer Research (AACR) Meeting in April 2015 (Dickler et al. 2015). This study enrolled 41 women with ER-positive, HER2-negative advanced breast cancer progressing after at least 6 months of endocrine therapy. ESR 1 mutation status was known in 19 patients (46\%) and was positive in nine patients. GDC-0810 was administered at total daily doses ranging from 100 to $800 \mathrm{mg}$, on a once- or twice-daily dosing regimen. Treatment-related adverse events included grade 1-2 diarrhea (63\%), fatigue (46\%), flatulence $(24 \%)$, vomiting $(22 \%)$, and anemia (22\%). The recommended phase II dose (RP2D) as a single agent was $600 \mathrm{mg}$ daily with food. At a median follow-up of 8 months, 13 of 31 patients (41\%) had stable disease beyond 6 months. Furthermore, two partial responses were seen, both in patients with ESR1 mutations. The phase IIa component of this study is ongoing. GDC-0810 is moving forward in clinical trial development. The randomized phase II HydranGea study will compare GDC0810 with the first-generation SERD, fulvestrant in women with advanced breast cancer resistant to aromatase inhibitors, including a defined subset with ESR1 mutations (https://www. clinicaltrials.gov/ct2/show/NCT02569801, accessed online 10 January 2016). Other agents in clinical trial development include GDC-0927 (SRN-927, Genentech Inc), AZD9496 (AstraZeneca), and LSZ102 (Novartis), which are currently being evaluated in dose-escalating phase I studies in women with ER+, Her2-negative advanced breast cancer (https://clinicaltrials.gov/ct2/ show/NCT02316509 and https://clinicaltrials.gov/ct2/ show/NCT02248090, accessed 23 February 2016).

Published by Bioscientifica Ltd 


\section{mTOR inhibitors}

Its position as a key downstream effector of the PI3K/AKT pathway makes mTOR an attractive target for therapies attempting to reverse emerging endocrine resistance. The phase II TAMRAD study evaluated the oral mTOR inhibitor everolimus in combination with tamoxifen vs tamoxifen alone in patients with metastatic ER+, HER2-negative breast cancer progressing after prior AI therapy (Bachelot et al. 2012). There was a significant improvement in the primary endpoint of 6-month CBR, which was $61 \%$ in the combination arm vs $42 \%$ in the tamoxifen alone arm. Time to progression and OS were also significantly improved with the addition of everolimus. Exploratory analysis suggested the benefit was largely confined to patients with secondary rather than primary endocrine resistance (i.e. patients whose breast cancer relapsed more than 6 months after completing adjuvant AI therapy or progressed after disease control for 6 months or more in the metastatic setting).

In the phase III Bolero 2 trial, everolimus in combination with the steroidal AI exemestane was compared with exemestane alone. This study enrolled patients with advanced ER+ HER2-negative breast cancer and progression after prior nonsteroidal AI therapy. It met its primary endpoint of locally assessed PFS (6.9 vs 2.8 months) and was stopped after an interim analysis (Baselga et al. 2012). The improvement in PFS is impressive but is accompanied by an increase in grade 3-4 toxicities including stomatitis (8\%), anemia (6\%), dyspnea (4\%), fatigue (4\%), hyperglycemia (4\%), and pneumonitis (3\%). The study was not powered to detect a difference in OS and the subsequent analysis of this endpoint was unsurprisingly negative (Piccart et al. 2014). Molecular analysis on archival tumor samples indicated that the benefit of everolimus in BOLERO-2 was independent of PIK3CA mutational status as well as alterations of other closely related genes (PTEN) and pathways (Hortobagyi et al. 2015). Subsequent analysis of cell-free DNA (cfDNA) extracted from archival plasma samples explored the correlation of selected ESR1 and PIK3CA mutations with outcomes in BOLERO-2 (Chandarlapaty et al. 2016, Moynahan et al. 2016). The two ESR1 mutations tested appeared to have differing effects on treatment, as patients with the D538G mutation demonstrated a PFS benefit with the addition of everolimus, while those with the Y537S mutation did not. Allele-specific assays for three hotspot mutations in PIK3CA were consistent with the archival tumor DNA results, indicating similar benefits with the addition of everolimus in PIK3CA-mutant and wild-type tumors. As expected, the selected ESR1 mutations were much more frequently identified in cfDNA vs archival tumor samples (28.4\% vs $1.3 \%)$, indicating a potential role for this technology in monitoring dynamic tumor genomic changes during treatment.

The improved outcomes seen with the addition of everolimus to AI therapy were not replicated in the phase III HORIZON study that added oral temsirolimus to firstline letrozole (Wolff et al. 2013). Potential explanations for the discrepancy between these two studies include the mTOR inhibitors used (temsirolimus vs everolimus) and differences in the study populations. Of particular note, patients participating in BOLERO-2 had prior AI exposure, whereas patients in HORIZON were AI-naïve and fewer than half had prior adjuvant tamoxifen. Thus, mTOR inhibition may be most useful in the setting of acquired endocrine resistance and may be of less utility in endocrine-responsive disease. The issue of optimal placement of mTOR inhibition in an endocrine therapy sequence is being explored in the phase III FEVEX study, which is enrolling patients with MBC previously treated with nonsteroidal AIs, and randomizing to a sequence of initial fulvestrant followed at progression by the exemestane-everolimus combination, vs the opposite sequence (https://clinicaltrials.gov/ct2/show/ NCT02404051, accessed online 10 March 2016).

\section{PI3K inhibitors}

With increased understanding of the complexity of intracellular signaling pathways, it has become apparent that inhibition of a given oncoprotein may result in an effect opposite to that intended (i.e. activation of the pathway) through relief of negative upstream feedback inhibition. These negative feedback regulatory mechanisms may be multiple and redundant: for the PI3K/AKT pathway, at least two mechanisms leading to PI3K activation as a consequence of mTOR inhibition have been identified (Chandarlapaty 2012). More proximal blockade (e.g. of PI3K) may obviate some of this feedback activation, improving pathway inhibition. Pictilisib (GDC-0941; Genentech Inc.) is an oral pan-inhibitor of class 1 PI3K (Folkes et al. 2008). The randomized phase II FERGI study enrolled 168 postmenopausal women with advanced ER+ breast cancer who had experienced disease progression on or after aromatase inhibitor therapy (Krop et al. 2014). Patients were randomized 1:1 to fulvestrant

Published by Bioscientifica Ltd 
with or without pictilisib $340 \mathrm{mg}$ daily. The PFS was not statistically improved for the combination arm vs fulvestrant alone in either the intention-to-treat or PIK3CA-mutant populations.

A second oral pan-class 1 PI3K inhibitor, BKM120 (buparlisib, Novartis), demonstrated robust target inhibition in preclinical studies, as well as synergistic activity with cytotoxic agents including taxanes (Maira et al. 2012). It demonstrated promising efficacy in combination with endocrine therapies in two phase I studies, with side effects that were more manageable with an intermittent ( 5 days on, 2 days off) oral dosing schedule (Mayer et al. 2014, Ma et al. 2015). Common AEs included fatigue, gastrointestinal disorders, transaminitis, hyperglycemia, mood disorders, and maculopapular rash. At the 2015 San Antonio Breast Cancer Symposium, results of the phase III BELLE-2 study were presented (Baselga et al. 2015). This study randomized 1147 women with advanced HR+ HER2-negative breast cancer progressing after prior AI therapy to fulvestrant with buparlisib or placebo. Patients were stratified by PIK3CA mutation status, assessed in archival tumor tissue. There was a modest PFS benefit in the overall study population (6.9 vs 5.0 months, HR $0.78, P<0.001)$. Among a subset of patients $(n=587)$ assessed for PIK3CA mutations in circulating tumor DNA (ctDNA), the results were more impressive with PFS of 7 vs 3.2 months for the combination vs fulvestrant alone in patients with ctDNA mutations (HR 0.56, $P<0.001)$. No significant difference between the two treatment arms was found among patients with PIK3CA mutations in archival tumor tissue, illustrating the inherent issues in utilizing archival tissue to interrogate dynamically evolving tumors, and the need to assess the current mutational profile whenever possible. Frequent discontinuations due to buparlisib-related adverse events may have limited the efficacy of combination therapy in this trial. Further evaluation of buparlisib is ongoing, including the phase III BELLE-3 study in patients previously treated with everolimus (https://clinicaltrials. gov/ct2/show/NCT01633060, accessed online 10 March 2016).

\section{Selective PI3K inhibitors}

Both pictilisib and buparlisib are pan-class 1 PI3K inhibitors (i.e. they inhibit all four p110 isoforms). There may be advantages to more limited isoform selectivity in some tumors, as this may facilitate an increase in the therapeutic drug exposure without increasing off-target side effects. Tumors with activating mutations in the PIK3CA gene would be expected to be sensitive to a drug selectively inhibiting the $\mathrm{p} 110 \alpha$ isoform, whereas PI3K signaling in PTEN-deficient tumors appears more dependent on the $\mathrm{p} 110 \beta$ isoform and may benefit from pan-class 1 inhibition (Wee et al. 2008, Jiang et al. 2010, Vanhaesebroeck et al. 2010, Schwartz et al. 2015). More selective compounds are entering clinical trials. GDC-0032 (taselisib; Genentech) is an inhibitor with isoform selectivity for PI3K $\alpha$ over PI3K $\beta$ (Ndubaku et al. 2013). In a phase II study, taselisib in combination with fulvestrant demonstrated an ORR of $22 \%$ in an endocrine-pretreated population (Dickler et al. 2016). PIK3CA mutations appear promising as a biomarker of efficacy in this study, with an ORR in the PIK3CAmutant cohort of $38.5 \%$ (compared with $10.5 \%$ in the wild-type cohort). These results support the stratification by PIK3CA mutation status in the ongoing phase III Sandpiper study evaluating the addition of taselisib to fulvestrant in patients with prior AI exposure, with a primary endpoint of PFS in PIK3CA-mutant tumors (https://clinicaltrials.gov/ct2/show/NCT02340221, accessed online 18 January 2016). BYL719 (alpelisib; Novartis) is a selective PI3K $\alpha$ inhibitor equipotent against wild-type and the most common activating mutations of PIK3CA (Fritsch et al. 2014). Not surprisingly, PTEN loss was a negative predictor of sensitivity, given the implication of PI3K $\beta$ in tumor development in a PTENdeficient setting as outlined above. The phase III SOLAR-1 study is currently accruing postmenopausal women and men with advanced HR+ HER2-negative breast cancer previously treated with AIs (https://clinicaltrials.gov/ct2/ show/NCT02437318, accessed online 18 January 2016). Study therapy consists of fulvestrant plus/minus apelisib. The clinical trial evaluation of apelisib in triplet regimens with endocrine therapy and CDK4/6 inhibition will be discussed in the next section. Meanwhile, a phase I/II study is evaluating the efficacy of GSK2636771, on oral PI3K $\beta$ isoform-specific inhibitor in patients with advanced PTEN-deficient solid tumors (Arkenau et al. 2014). This agent has $>900$-fold selectivity for PI3K $\beta$ over PI3K $\alpha$. Preliminary results established an MTD of $400 \mathrm{mg}$ daily, with early signals of antitumor efficacy in this cohort of patients. Toxicity with PI3K inhibitors can occur even with isoform selectivity, representing unwanted 'on target' rather than 'off target' effects. For example, p110 $\alpha$ inhibitors have inevitable effects on glucose homeostasis requiring careful management; development of even more highly selective inhibitors targeting hotspot mutations implicated in tumorigenesis would be advantageous.

Published by Bioscientifica Ltd 


\section{CDK4/6 inhibitors}

The first drugs developed to target cell cycle progression abnormalities in human cancers were relatively nonselective pan-CDK inhibitors such as flavopiridol, which were limited by off-target effects and complex administration requirements (Sedlacek et al. 1996, Fornier et al. 2007). The therapeutic potential of this strategy in breast cancer was boosted by the development of highly selective inhibitors of CDK4/6 including palbociclib, ribociclib, and abemaciclib. Palbociclib (Ibrance; Pfizer Inc), formerly PD0332991, is the most clinically advanced CDK4/6 inhibitor. Two phase I studies in patients with $\mathrm{Rb}$-positive tumors established a dose of $125 \mathrm{mg}$ daily on a 3 week on, 1 week off schedule as the recommended phase II dose (RP2D) (Schwartz et al. 2011, Flaherty et al. 2012). Myelosuppression (particularly neutropenia) emerged as a common toxicity. The most common non-hematological adverse events were fatigue, diarrhea, nausea, and constipation and were of mainly low grade. Single-agent palbociclib at the RP2D was evaluated in a phase II study in patients with Rb-positive advanced breast cancer (DeMichele et al. 2013). Partial responses were seen in two of 28 (7\%) evaluable patients, with stable disease greater than 6 months in $14 \%$. No responses or prolonged disease stabilizations were seen in patients with ER-negative tumors. The disappointing single-agent activity observed in this chemotherapy pretreated population suggests a potential cross-resistance with chemotherapy and increases the attractiveness of combining palbociclib with other agents, notably endocrine therapy.

The multicenter randomized phase I/II PALOMA-1 study evaluated the combination of palbociclib (at $125 \mathrm{mg}$ orally each day on the $3 / 1$ schedule) with letrozole $2.5 \mathrm{mg}$ daily vs letrozole alone in the first-line treatment of ER-positive/HER2-negative advanced breast cancer in postmenopausal women. An initial phase I portion of letrozole plus palbociclib evaluated safety and tolerability of the combination in an unselected population. The phase II component of the study was divided into two parts, the first enrolling patients selected only by ER/HER2 status and the second part enrolling patients further selected for CCND1 amplification and/or p16 loss; 66 patients were enrolled in part 1 and 99 in part 2. Exploratory analysis revealed no additional predictive value of CCND1 status or p16 loss for palbociclib efficacy over ER status alone, and consequently parts 1 and 2 were combined for an overall efficacy analysis. Finn et al. (2015) reported the final PFS efficacy analysis, revealing an impressive improvement in PFS in the combination arm (20.2 vs 10.2 months,
$P=0.0004)$. A significant difference in OS had not yet been seen at this analysis. On Feb 3rd 2015, the FDA granted accelerated approval for palbociclib in combination with letrozole for the first-line treatment of women with ER+, HER2-negative advanced or metastatic breast cancer (US Food and Drugs Administration 2016). The phase III PALOMA-2 study mirrored the phase II component of PALOMA-1, with a randomization between letrozole plus palbociclib vs letrozole alone in a larger patient population of 666 women with advanced, previously untreated ER+, HER2-negative breast cancer (Finn et al. 2016). The results confirmed the improvement in PFS seen in PALOMA-1, with a clinically and statistically significant improvement in investigator assessed PFS from 14.5 to 24.8 months. Neutropenia was more common as expected in the combination arm ( $80 \%$ vs $6 \%$ ), although neutropenic fever remained uncommon (1.6\% vs $0 \%$ ). These data support the accelerated approval granted to palbociclib in this treatment setting by the FDA based on the PALOMA-1 results.

Meanwhile, the phase III PALOMA-3 study investigated hormonal therapy plus palbociclib in premenopausal and postmenopausal patients whose disease had progressed after prior endocrine therapy. The endocrine therapy utilized in PALOMA-3 was the SERD fulvestrant, with co-administration of the luteinizing hormone releasing hormone (LHRH) analog goserelin in premenopausal patients to induce chemical menopause. Following a pre-planned interim analysis, Turner et al. (2015) reported an improvement in median PFS from 3.8 months in the placebo-fulvestrant arm to 9.2 months in the palbociclib-fulvestrant arm (HR $0.42,95 \%$ CI $0.32,0.56 ; P<0.001)$. The most common adverse events reported were hematological, with neutropenia occurring in $79 \%$ of patients in the palbociclib arm vs $3 \%$ in the placebo arm, and leukopenia occurring in $46 \%$ vs $4 \%$. Febrile neutropenia was not increased in the palbociclibcontaining arm, occurring in $0.6 \%$ of patients in both arms. The relatively poor performance of the fulvestrant alone in this study likely reflects the young age and more adverse disease characteristics of the patient population. Nevertheless, the clinically significant improvement in PFS with the addition of palbociclib indicates a key role for CDK4/6 inhibition in overcoming endocrine resistance in the clinical practice. In February 2016, the FDA expanded the approval of palbociclib to include therapy in combination with fulvestrant for HR+, HER2negative advanced or metastatic breast cancer in women with disease progression following endocrine therapy. The role for a combination of endocrine therapy with CDK4/6

Published by Bioscientifica Ltd 
inhibition as an alternative to chemotherapy in breast cancer with emerging endocrine resistance is being put to the test in the PEARL study (https://clinicaltrials.gov/ct2/ show/NCT02028507, accessed online 11 January 2016). This ongoing randomized phase III study is comparing palbociclib plus exemestane vs the oral chemotherapy drug capecitabine in patients with advanced ER-positive, HER2-negative MBC, who have progressed on prior treatment with a nonsteroidal aromatase inhibitor.

Other highly selective CDK4/6 inhibitors including ribociclib and abemaciclib are being evaluated in ER+ breast cancer. Ribociclib (Novartis) demonstrates activity in models of endocrine resistance, including activating aberrations of PIK3CA and/or HER2 (Kim et al. 2013). The phase III Monaleesa-2 study is comparing letrozole plus ribociclib to letrozole alone in women with previously untreated HR+, HER2-negative advanced breast cancer (https://clinicaltrials.gov/ct2/show/NCT01958021, accessed online 11 January 2016). On May 18th 2016, Novartis issued a press release indicating that the independent Data Monitoring Committee had recommended stopping the trial early after a pre-planned interim analysis showed it had met its primary endpoint of a clinically meaningful improvement in PFS with the combination therapy (https://www.novartis.com/ news/media-releases/monaleesa-2-trial-novartis-lee011ribociclib-stopped-due-positive-efficacy, accessed online 25 May 2016). Detailed results of the study are expected to be presented at an international meeting later in 2016. Notable ongoing breast cancer studies include two phase Ib/II studies assessing rational triplet regimens in endocrine-resistant breast cancer: ribociclib in combination with letrozole and the PI3K inhibitor apelisib (http://clinicaltrials.gov/ct2/show/NCT01872260, accessed online 11 January 2016), and in combination with the steroidal aromatase inhibitor exemestane and the mTOR inhibitor everolimus (http://clinicaltrials.gov/ ct2/show/NCT01857193, accessed online 23 February 2016). These combinations are attractive given preclinical evidence that CDK4/6 inhibition may overcome intrinsic and adaptive resistance to PI3K inhibition (Vora et al. 2014). Preliminary data from 16 patients enrolled in the exemestane/everolimus/ribociclib combination study indicate that the triplet combination appears feasible (Bardia et al. 2014). The dose expansion phase will further explore tolerability of the triplet in patients naïve to CDK4/6 therapy and of the exemestane/ribociclib doublet in patients with prior CDK4/6 inhibitor therapy. Similarly, phase I data for the doublet combinations of ribociclib/letrozole and ribociclib/apelisib have been presented (Munster et al. 2014). Both arms demonstrated acceptable safety profiles, with neutropenia observed as expected with ribociclib. Accrual to the third arm (ribociclib, apelisib plus letrozole) will proceed, followed by a planned phase 2 randomization between the triplet and the two doublets.

Abemaciclib (Eli Lilly) was evaluated in a phase I study across multiple tumor types, including a cohort of 47 women with heavily pretreated metastatic breast cancer. Tumor responses were confined to women with $\mathrm{ER}+$ disease, with a response rate of $25 \%$ (nine of 36) in this subset (Patnaik et al. 2014a). The disease control rate (defined for this study as partial responses plus stable disease of any duration) was $81 \%$ in the ER+ subset. Neutropenia was the only grade $3 / 4$ adverse event seen in more than $5 \%$ of patients, occurring in $11 \%$. A separate MBC cohort $(n=13)$ evaluated the combination of abemaciclib $200 \mathrm{mg}$ twice daily plus fulvestrant (Patnaik et al. 2014b). The most common possibly treatment-related AEs were diarrhea ( $8 \%$ G3), fatigue, neutropenia, nausea, vomiting, and leukopenia. There were no episodes of febrile neutropenia. Of these, eight confirmed and three unconfirmed partial responses were observed. Ongoing studies are assessing abemaciclib in the HR+ breast cancer population, both as monotherapy and in combination with endocrine agents. The phase II MONARCH1 study evaluated continuous oral dosing of abemaciclib (200 mg twice daily) in patients with HR+ MBC who had received prior endocrine therapy and one to two prior chemotherapy regimens, including taxanes (Dickler et al. 2016). The ORR was 19.7\%, which is similar to that seen with single-agent chemotherapy in this setting, with a median duration of response of 8.6 months. Diarrhea was a common adverse event, occurring at grade 3 in $19.7 \%$ of patients. This was commonly seen early in therapy and resolved quickly with therapy interruption, antidiarrheal agents, and dose reduction. The phase III MONARCH2 study is comparing the combination of fulvestrant plus continuous daily oral abemaciclib vs fulvestrant alone in patients with advanced breast cancer and prior endocrine therapy (http://clinicaltrials.gov/ct2/ show/NCT02107703. Accessed online 11 January 2016).

\section{Other therapies: inhibitors of FGFR, IGFR, HDAC, and autophagy}

Dovitinib is an oral multi-targeting tyrosine kinase inhibitor that includes fibroblast growth factor (FGFR) 1-3 among its targets. A phase II trial evaluated dovitinib in 81 women with $\mathrm{HR}+$ and HR-negative metastatic

Published by Bioscientifica Ltd 
breast cancer; unconfirmed responses and stable disease $>6$ months were seen in $25 \%$ of HR+ tumors with FGFR1 amplification compared with $3 \%$ of patients with HR-negative FGFR1 non-amplified disease (André et al. 2013). Current studies include a randomized phase II study evaluating fulvestrant plus/minus dovitinib in patients with prior endocrine therapy (https://www.clinicaltrials. gov/ct2/show/NCT01528345, accessed online 28 February 2016) and a phase I/II study adding dovitinib to aromatase inhibitor therapy in patients experiencing progression on aromatase inhibitor monotherapy (André \& Cortés 2015). Molecular pre-screening to test for FGFR pathway activation is included in the eligibility criteria for these studies. Ongoing studies are evaluating additional FGFR targeting agents AZD4547, lucitanib, BGJ398, and JNJ42756493 in breast cancer (https://www.clinicaltrials.gov/ ct $2 /$ results?term $=\% 22$ FGFR $\% 22+A N D+\% 22$ breast+cance r\%22\&recr=Open, accessed online 28 February 2016).

Inhibition of insulin-like growth factor receptor 1 (IGFR1) with the monoclonal antibody AMG-479 (ganitumumab) has been tested in a randomized phase II study in endocrine-pretreated HR+ breast cancer, with no improvement in PFS (Robertson et al. 2013). The oral inhibitor of histone deacetylase (HDAC) entinostat in combination with exemestane prolonged DFS and OS over exemestane alone in a randomized phase II study in patients with prior nonsteroidal AI therapy (Yardley et al. 2013). A randomized phase III study is currently accruing to compare entinostat and exemestane to the endocrine therapy alone in patients with advanced HR+ breast cancer and prior nonsteroidal AI treatment (https:// www.clinicaltrials.gov/ct2/show/NCT02115282, accessed online 19 Jan 2016).

The antimalarial drug chloroquine and antilupus drug hydroxychloroquine are known to be inhibitors of autophagy and are currently being explored in early phase trials in breast cancer. In a double-blind randomized phase II 'window' trial, patients are receiving to 2-6weeks of chloroquine treatment leading up to surgery for their breast cancer, with outcomes including effects on tumor proliferation and apoptosis being measured (https://www.clinicaltrials.gov/ct2/show/ NCT02333890, accessed online 23 May 2016). In a similar preoperative window setting, the PINC study is examining the effect of neoadjuvant chloroquine on the ability of ductal carcinoma in situ (DCIS) to survive and invade (https://www.clinicaltrials.gov/ct2/show/ NCT01023477, accessed online 23 May 2016). Meanwhile in the advanced endocrine-resistant breast cancer setting, hydroxychloroquine is being evaluated in combination with endocrine therapy in a phase Ib/II study (https:// www.clinicaltrials.gov/ct2/show/NCT02414776, accessed online 23 May 2016).

\section{Conclusion}

Endocrine therapy can provide prolonged disease control in HR+ advanced breast cancer, and strategies to prolong the utility of endocrine therapy are highly desirable. Although our understanding of the mechanisms underlying the emergence of endocrine resistance has improved greatly, the results of clinical trials have been mixed. Notable successes include the FDA approval of agents targeting mTOR and CDK4/6 in combination with endocrine therapy, whereas failures include the disappointing performance of pan-PI3K inhibition with pictilisib. Increasing target selectivity may improve efficacy while decreasing off-target toxicity, as has been seen with newer CDK4/6 inhibitors compared with earlier pan-CDK inhibitors. It is hoped that similar enhanced clinical utility will be seen with isoform-selective PI3K inhibitors. Similarly, efforts to develop next-generation SERDs combining improved oral bioavaliability with enhanced ER targeting appear promising.

An additional approach to overcome endocrine resistance is to target multiple intracellular pathways and/or multiple points within a pathway. This approach tackles the built-in redundancy within signaling pathways and attempts to prevent iatrogenic release of regulatory feedback inhibition with compensatory pathway stimulation. It does carry the risk of increased toxicity. This strategy is being explored in current trials exploring the tolerability and efficacy of triplet regimens (including antiestrogen/mTOR/CDK inhibitor and antiestrogen/PI3K/CDK inhibitor combinations) in advanced breast cancer.

Finally, it is imperative that we continue to strive to understand the dynamic changes that take place over the course of treatment in individual cancers. The recognition of the emergence of ESR1 mutations during endocrine therapy underlines the importance of repeated sampling of tumors over time, whether that be with tumor tissue biopsies or 'liquid biopsies', i.e. circulating tumor cells and circulating DNA. Tumor heterogeneity may exist and/or develop over time, such that 'liquid biopsies' may better represent the molecular alterations underlying the biology of the cancer. Validation studies are underway to compare these two approaches. Analyses of tumor and cfDNA samples from patients participating in clinical trials are beginning to create a landscape where therapy

Published by Bioscientifica Ltd 
selection for individual patients may be assisted by interrogating the current mutational profile of the tumor. Patients with ESR1 mutations may be better served by a SERD than an AI, for example while PIK3CA mutations do not appear to affect mTOR inhibitor therapy efficacy but appear to be a biomarker for PI3K inhibitor efficacy. Continued collection of tissue and plasma samples from patients participating in clinical trials is vital in order to refine a dynamic genomic-based approach to therapy selection. Such an approach will bring endocrine therapy for breast cancer closer to the ultimate goal of personalized medicine: getting 'the right drug for the right patient at the right dose and time' (Sadee \& Dai 2005).

\section{Declaration of interest}

M N Dickler reports consulting work for Roche/Genentech, Pfizer, Astra Zeneca, and Novartis. C G Murphy reports travel support from Roche/ Genentech.

\section{Funding}

This research did not receive any specific grant from any funding agency in the public, commercial, or not-for-profit sector.

\section{References}

André F \& Cortés J 2015 Rationale for targeting fibroblast growth factor receptor signaling in breast cancer. Breast Cancer Research and Treatment 150 1-8. (doi:10.1007/s10549-015-3301-y)

André F, Bachelot T, Campone M, Dalenc F, Perez-Garcia JM, Hurvitz SA Turner N, Rugo H, Smith JW, Deudon S, et al. 2013 Targeting FGFR with dovitinib (TKI258): preclinical and clinical data in breast cancer. Clinical Cancer Research 19 3693-3702. (doi:10.1158/10780432.CCR-13-0190)

Arkenau H-T, Mateo J, Lemech CR, Infante JR, Burris HA, Bang Y-J, Eder JP, Herbst RS, Sharma S, Chung HC, et al. 2014 A phase I/II, first-in-human dose-escalation study of GSK2636771 in patients (pts) with PTEN-deficient advanced tumors. Journal of Clinical Oncology 32 (May 20 Supplement) abstract 2514. (available at: http://meeting. ascopubs.org/cgi/content/abstract/32/15_suppl/2514)

Arthur LM, Turnbull AK, Renshaw L, Keys J, Thomas JS, Wilson TR, Lackner MR, Sims AH \& Dixon JM 2014 Changes in PIK3CA mutation status are not associated with recurrence, metastatic disease or progression in endocrine-treated breast cancer. Breast Cancer Research and Treatment 147 211-219. (doi:10.1007/s10549014-3080-x)

Bachelot T, Bourgier C, Cropet C, Ray-Croquard I, Ferrero JM, Freyer G, Abadie-Lacourtoisie S, Eymard JC, Debled M, Spaëth D, et al. 2012 Randomized phase II trial of everolimus in combination with tamoxifen in patients with hormone receptor-positive, human epidermal growth factor receptor 2-negative metastatic breast cancer with prior exposure to aromatase inhibitors: a GINECO study. Journal of Clinical Oncology 30 2718-2724. (doi:10.1200/ JCO.2011.39.0708)

Bardia A, Modi S, Chavez-Mac Gregor M, Kittaneh M, Marino AJ, Matano A, Bhansali S, HewesB \& Cortes J 2014 Phase Ib/II study of LEE011, everolimus, and exemestane in postmenopausal women with ER+/HER2-metastatic breast cancer. Journal of Clinical Oncology
32 (May 20 Supplement) abstract 535. (available at: http://meeting. ascopubs.org/cgi/content/abstract/32/15_suppl/535)

Baselga J, Campone M, Piccart M, Burris HA, Rugo HS, Sahmoud T, Noguchi S, Gnant M, Pritchard KL, Lebrun F, et al. 2012 Everolimus in postmenopausal hormone-receptor-positive advanced breast cancer. New England Journal of Medicine 366 520-529. (doi:10.1056/ NEJMoa1109653)

Baselga J, Im S-A, Iwata H, Clemons M, Ito Y, Awada A, Chia S, Jagiello-Gruszfeld A, Pistilli B, Tseng L-M, et al. 2015 PIK3CA status in circulating tumor DNA (ctDNA) predicts efficacy of buparlisib (BUP) plus fulvestrant (FULV) in postmenopausal women with endocrine-resistant HR+/HER2- advanced breast cancer (BC): first results from the randomized, phase III BELLE-2 trial. 38th Annual CTRC/AACR San Antonio Breast Cancer Symposium. San Antonio, Texas, USA; December 8-12. Cancer Research 76 (Supplement) abstract S6-01. (doi:10.1158/1538-7445. sabcs15-s6-01)

Bosch A, Li Z, Bergamaschi A, Ellis H, Toska E, Prat A, Tao JJ, Spratt DE, Viola-Villegas NT, Castel P, et al. 2015 PI3K inhibition results in enhanced estrogen receptor function and dependence in hormone receptor-positive breast cancer. Science Translational Medicine $\mathbf{7}$ 283ra51. (doi:10.1126/scitranslmed.aaa4442)

Campbell IG, Russell SE, Choong DY, Montgomery KG, Ciavarella ML, Hooi CS, Cristiano BE, Pearson RB \& Phillips WA 2004 Mutation of the PIK3CA gene in ovarian and breast cancer. Cancer Research 64 7678-7681. (doi:10.1158/0008-5472.CAN-04-2933)

Cancer Genome Atlas Network 2012 Comprehensive molecular portraits of human breast tumours. Nature 490 61-70. (doi:10.1038/ nature11412)

Chandarlapaty S 2012 Negative feedback and adaptive resistance to the targeted therapy of cancer. Cancer Discovery 2 311-319. (doi:10.1158/2159-8290.CD-12-0018)

Chandarlapaty S, Sung P, Chen D, He W, Samoila A, You D, Bhatt T, Patel P, Voi M, Gnant M, et al. 2016 S2-07: cfDNA analysis from BOLERO-2 plasma samples identifies a high rate of ESR1 mutations: exploratory analysis for prognostic and predictive correlation of mutations reveals different efficacy outcomes of endocrine therapy-based regimens. 38th Annual CTRC/AACR San Antonio Breast Cancer Symposium. San Antonio, Texas, USA; December 8-12. Cancer Research 76 (Supplement) abstract S2-07. (doi:10.1158/15387445.sabcs15-s2-07)

Chia S, Gradishar W, Mauriac L, Bines J, Amant F, Federico M, Fein L, Romieu G, Buzdar A, Robertson JF, et al. 2008 Double-blind, randomized placebo controlled trial of fulvestrant compared with exemestane after prior nonsteroidal aromatase inhibitor therapy in postmenopausal women with hormone receptor-positive, advanced breast cancer: results from EFECT. Journal of Clinical Oncology 26 1664-1670. (doi:10.1200/JCO.2007.13.5822)

Clarke R, Tyson JJ \& Dixon JM 2015 Endocrine resistance in breast cancer - an overview and update. Molecular and Cellular Endocrinology 418 220-234. (doi:10.1016/j.mce.2015.09.035)

DeMichele A, Sanders Clark A, Heitjan D, Randolph S, Gallagher M, Lal P, Feldman MD, Zhang PJ, Schnader A, Zafman K, et al. 2013 A phase II trial of an oral CDK 4/6 inhibitor, PD0332991, in advanced breast cancer. Journal of Clinical Oncology 31 (May 20 Supplement) abstract 519. (available at: http://meeting.ascopubs.org/cgi/content/ abstract/31/15_suppl/519)

Di Leo A, Jerusalem G, Petruzelka L, Torres R, Bondarenko IM, Khasanov R, Verhoeven D, Pedrini JL, Smirnova I, Lichinitser MR, et al. 2010 Results of the CONFIRM Phase III trial comparing fulvestrant $250 \mathrm{mg}$ with fulvestrant $500 \mathrm{mg}$ in postmenopausal women with estrogen receptor- positive advanced breast cancer. Journal of Clinical Oncology 28 4594-4600. (doi:10.1200/ JCO.2010.28.8415)

Di Leo A, Jerusalem G, Petruzelka L, Torres R, Bondarenko IN, Khasanov R, Verhoeven D, Pedrini JL, Smirnova I, Lichinitser MR,

Published by Bioscientifica Ltd. 
et al. 2014 Final overall survival: fulvestrant $500 \mathrm{mg}$ vs $250 \mathrm{mg}$ in the randomized CONFIRM trial. Journal of the National Cancer Institute 106 djt337. (doi:10.1093/jnci/djt337)

Dickler MN, Bardia A, Mayer I, Winer E, Rix P, Hager J, Chen M, Chan I, Chow-Maneval E, Arteaga C, et al. 2015 A first-in-human phase I study to evaluate the oral selective estrogen receptor degrader GDC0810 (ARN-810) in postmenopausal women with estrogen receptor+ HER2-, advanced/metastatic breast cancer. Proceedings of the AACR 106th Annual Meeting 2015; April 18-22, 2015; Philadelphia, PA, USA. Cancer Research 75 (Supplement) abstract CT231. (doi:10.1158/1538-7445.am2015-ct231)

Dickler MN, Tolaney SM, Rugo HS, Cortes J, Dieras V, Patt DA, Wildiers H, Frenzel M, Koustenis A \& Baselga J 2016 MONARCH1: results from a phase II study of abemaciclib, a CDK4 and CDK6 inhibitor, as monotherapy, in patients with HR+/HER2- breast cancer, after chemotherapy for advanced disease. Journal of Clinical Oncology 34 (Supplement) abstract 510. (available at: http:// meetinglibrary.asco.org/content/164546-176)

Dickler MN, Saura C, Richards DA, Krop IE, Cervantes A, Bedard PL, Patel MR, Pusztai L, Oliveira M, Ware JA, et al. 2016 A phase II study of the PI3K inhibitor taselisib (GDC-0032) combined with fulvestrant (F) in patients (pts) with HER2-negative (HER2-), hormone receptorpositive (HR+) advanced breast cancer (BC). Journal of Clinical Oncology 34 (Supplement) abstract 520. (available at: http:// meetinglibrary.asco.org/content/165518-176)

Ellis MJ, Llombart-Cussac A, Feltl D, Dewar JA, Jasiówska M, Hewson N, Rukazenkov Y \& Robertson JF 2015 Fulvestrant $500 \mathrm{mg}$ Versus Anastrozole $1 \mathrm{mg}$ for the first-line treatment of advanced breast cancer: overall survival analysis from the phase II first study. Journal of Clinical Oncology 33 3781-3787. (doi:10.1200/JCO.2015.61.5831)

Ellis MJ, Tao Y, Young O, White S, Proia AD, Murray J, Renshaw L, Faratian D, Thomas J, Dowsett M, et al. 2006 Estrogen-independent proliferation is present in estrogen-receptor HER2-positive primary breast cancer after neoadjuvant letrozole. Journal of Clinical Oncology 24 3019-3025. (doi:10.1200/JCO.2005.04.3034)

Ellis MJ, Tao Y, Luo J, A'Hern R, Evans DB, Bhatnagar AS, Chaudri Ross HA, von Kameke A, Miller WR, Smith I, et al. 2008 Outcome prediction for estrogen receptor-positive breast cancer based on postneoadjuvant endocrine therapy tumor characteristics. Journal of the National Cancer Institute 100 1380-1388. (doi:10.1093/ jnci/djn309)

Fawell SE, White R, Hoare S, Sydenham M, Page M \& Parker MG 1990 Inhibition of estrogen receptor-DNA binding by the 'pure' antiestrogen ICI 164,384 appears to be mediated by impaired receptor dimerization. PNAS 87 6883-6887. (doi:10.1073/pnas.87.17.6883)

Finn RS, Dering J, Conklin D, Kalous O, Cohen DJ, Desai AJ, Ginther C, Atefi M, Chen I, Fowst C, et al. 2009 PD 0332991, a selective cyclin D kinase 4/6 inhibitor, preferentially inhibits proliferation of luminal estrogen receptor-positive human breast cancer cell lines in vitro. Breast Cancer Research 11 R77. (doi:10.1186/bcr2419)

Finn RS, Crown JP, Lang I, Boer K, Bondarenko IM, Kulyk SO, Ettl J, Patel R, Pinter T, Schmidt M, et al. 2015 The cyclin-dependent kinase $4 / 6$ inhibitor palbociclib in combination with letrozole versus letrozole alone as first-line treatment of oestrogen receptor-positive, HER2-negative, advanced breast cancer (PALOMA-1/TRIO-18): a randomised phase 2 study. Lancet Oncology 16 25-35. (doi:10.1016/ S1470-2045(14)71159-3)

Finn RS, Martin M, Rugo HS, Jones SE, Im S-A, Gelmon KA, Harbeck N, Lipatov ON, Walshe JM, Moulder SL, et al. 2016 PALOMA-2: primary results from a phase III trial of palbociclib (P) with letrozole (L) compared with letrozole alone in postmenopausal women with ER+/HER2- advanced breast cancer (ABC). Journal of Clinical Oncology 34 (Supplement) abstract 507. (available at: http://meetinglibrary. asco.org/content/165131-176)

Flaherty KT, Lorusso PM, Demichele A, Abramson VG, Courtney R, Randolph SS, Shaik MN, Wilner KD, O'Dwyer PJ \& Schwartz GK
2012 Phase I, dose escalation trial of the oral cyclin-dependent kinase 4/6 inhibitor PD 0332991, administered using a 21-day schedule in patients with advanced cancer. Clinical Cancer Research 18 568-576. (doi:10.1158/1078-0432.CCR-11-0509)

Folkes AJ, Ahmadi K, Alderton WK, Alix S, Baker SJ, Box G, Chuckowree IS, Clarke PA, Depledge P, Eccles SA, et al. 2008 The identification of 2-(1H-indazol-4-yl)-6-(4-methanesulfonylpiperazin-1-ylmethyl)-4-morpholin-4-yl-t hieno[3,2-d]pyrimidine (GDC-0941) as a potent, selective, orally bioavailable inhibitor of class I PI3 kinase for the treatment of cancer. Journal of Medicinal Chemistry 51 5522-5532. (doi:10.1021/jm800295d)

Fornier MN, Rathkopf D, Shah M, Patil S, O'Reilly E, Tse AN, Hudis C, Lefkowitz R, Kelsen DP \& Schwartz GK 2007 Phase I dose-finding study of weekly docetaxel followed by flavopiridol for patients with advanced solid tumors. Clinical Cancer Research 13 5841-5846. (doi:10.1158/1078-0432.CCR-07-1218)

Fox EM, Miller TW, Balko JM, Kuba MG, Sanchez V, Smith RA, Liu S, Gonzalez-Angulo AM, Mills GB, Ye F, et al. 2011 A kinome-wide screen identifies the insulin/IGF-I receptor pathway as a mechanism of escape from hormone dependence in breast cancer. Cancer Research 71 6773-6784 (doi:10.1158/0008-5472.CAN-11-1295)

Fribbens C, O'Leary B, Kilburn L, Hrebien S, Garcia-Murillas J, Beaney M, Cristofanilli M, Andre F, Loi S, Loibl S, et al. 2016 Plasma ESR1 mutations and the treatment of estrogen receptor-positive advanced breast cancer. Journal of Clinical Oncology [in press]. (doi:10.1200/JCO.2016.67.3061)

Fritsch C, Huang A, Chatenay-Rivauday C, Schnell C, Reddy A, Liu M, Kauffmann A, Guthy D, Erdmann D, De Pover A, et al. 2014 Characterization of the novel and specific PI3K $\alpha$ inhibitor NVP-BYL719 and development of the patient stratification strategy for clinical trials. Molecular Cancer Therapeutics 13 1117-1129. (doi:10.1158/1535-7163.MCT-13-0865)

Frogne T, Benjaminsen RV, Sonne-Hansen K, Sorenson BS, Nexo E, Laenkholm AV, Rasmussen LM, Riese DJ, de Cremoux P, Stenvang J, et al. 2009 Activation of ErbB3, EGFR and Erk is essential for growth of human breast cancer cell lines with acquired resistance to fulvestrant. Breast Cancer Research and Treatment 121 601-613. (doi:10.1007/s10549-008-0011-8)

Fu X, Osborne CK \& Schiff R 2013 Biology and therapeutic potential of PI3K signaling in ER+/HER2-negative breast cancer. Breast 22 S12-S18. (doi:10.1016/j.breast.2013.08.001)

Ghayad SE, Bieche I, Vendrell JA, Keime C, Lidereau R, Dumontet C \& Cohen PA 2008 mTOR inhibition reverses acquired endocrine therapy resistance of breast cancer cells at the cell proliferation and gene-expression levels. Cancer Science 99 1992-2003. (doi:10.1111/j.1349-7006.2008.00955.x)

Hammond ME, Hayes DF, Dowsett M, Allred DC, Hagerty KL, Badve S, Fitzgibbons PL, Francis G, Goldstein NS, Hayes M, et al. 2010 American Society of Clinical Oncology/College of American Pathologists guideline recommendations for immunohistochemical testing of estrogen and progesterone receptors in breast cancer. Journal of Clinical Oncology 28 2784-2795. (doi:10.1200/ JCO.2009.25.6529)

Hortobagyi GN, Chen D, Piccart M, Rugo HS, Burris HA, Pritchard KI, Campone M, Noguchi S, Perez AT, Deleu I, et al. 2015 Correlative analysis of genetic alterations and everolimus benefit in hormone receptor-positive, human epidermal growth factor receptor 2-negative advanced breast cancer: results from BOLERO-2. Journal of Clinical Oncology 34 419-426. (doi:10.1200/ JCO.2014.60.1971)

Howell A, Robertson JFR, Quaresma Albano J, Aschermannova A, Mauriac L, Kleeberg UR, Vergote I, Erikstein B, Webster A \& Morris C 2002 Fulvestrant, formerly ICI 182,780 , is as effective as anastrozole in postmenopausal women with advanced breast cancer progressing after prior endocrine treatment. Journal of Clinical Oncology 20 3396-3403. (doi:10.1200/JCO.2002.10.057) 
Jeselsohn R, Yelensky R, Buchwalter G, Frampton G, Meric-Bernstam F, Gonzalez-Angulo AM, Ferrer-Lozano J, Perez-Fidalgo JA, Cristofanilli M, Gomez H, et al. 2014 Emergence of constitutively active estrogen receptor- $\alpha$ mutations in pretreated advanced estrogen receptor-positive breast cancer. Clinical Cancer Research 20 1757-1767. (doi:10.1158/1078-0432.CCR-13-2332)

Jiang X, Chen S, Asara JM \& Balk SP 2010 Phosphoinositide 3-kinase pathway activation in phosphate and tensin homolog (PTEN)-deficient prostate cancer cells is independent of receptor tyrosine kinases and mediated by the p110beta and p110delta catalytic subunits. Journal of Biologic Chemistry 285 14980-14989. (doi:10.1074/jbc.M109.085696)

Johnston SR, Kilburn LS, Ellis P, Dodwell D, Cameron D, Hayward L, Im YH, Braybooke JP, Brunt AM, Cheung KL, et al. 2013 Fulvestrant plus anastrozole or placebo versus exemestane alone after progression on non-steroidal aromatase inhibitors in postmenopausal patients with hormone-receptor-positive locally advanced or metastatic breast cancer (SoFEA): a composite, multicentre, phase 3 randomised trial. Lancet Oncology 14 989-998. (doi:10.1016/S1470-2045(13)70322-X)

Kim S, Loo A, Chopra R, Caponigro G, Huang A, Vora S, Parasuraman S, Howard S, Keen N, Sellers W, et al. 2013 LEE011: an orally bioavailable, selective small molecule inhibitor of $\mathrm{CDK} 4 / 6$ - reactivating $\mathrm{Rb}$ in cancer. Proceedings of the AACR-NCIEORTC International Conference: Molecular Targets and Cancer Therapeutics, Oct 19-23, Boston, MA, USA. Molecular Cancer Therapeutics 12 (11 Supplement) abstract PR02. (doi:10.1158/15357163.targ-13-pr02)

Krop I, Johnston S, Mayer IA, Dickler M, Ganju V, Forero-Torres A, Melichar B, Morlaes S, de Boer R, Gendreau S, et al. 2014 The FERGI phase II study of the PI3K inhibitor pictilisib (GDC-0941) plus fulvestrant vs fulvestrant plus placebo in patients with ER+, aromatase inhibitor (AI)-resistant advanced or metastatic breast cancer - part I results. 37th Annual CTRC/AACR San Antonio Breast Cancer Symposium, San Antonio, TX, USA; December 9-13. Cancer Research 75 (Supplement) abstract S2-02. (doi:10.1158/1538-7445. sabcs14-s2-02)

Lai A, Kahraman M, Govek S, Nagasawa J, Bonnefous C, Julien J , Douglas K, Sensintaffar J, Lu N, Lee KJ, et al. 2015 Identification of GDC-0810 (ARN-810), an orally bioavailable selective estrogen receptor degrader (SERD) that demonstrates robust activity in tamoxifen-resistant breast cancer xenografts. Journal of Medicinal Chemistry 58 4888-4904. (doi:10.1021/acs.jmedchem.5b00054)

Lauring J, Park BH \& Wolff AC 2013 The phosphoinositide-3-kinase-AktmTOR pathway as a therapeutic target in breast cancer. Journal of the National Comprehensive Cancer Network 11 670-678.

Levine DA, Bogomolniy F, Yee CJ, Lash A, Barakat RR, Borgen PI \& Boyd J 2005 Frequent mutation of the PIK3CA gene in ovarian and breast cancers. Clinical Cancer Research 11 2875-2878. (doi:10.1158/1078-0432.CCR-04-2142)

Li S, Shen D, Shao J, Crowder R, Liu W, Prat A, He X, Liu S, Hoog J, Lu C, et al. 2013 Endocrine-therapy-resistant ESR1 variants revealed by genomic characterization of breast-cancer-derived xenografts. Cell Reports 4 1116-1130. (doi:10.1016/j.celrep.2013.08.022)

Loi S, Haibe-Kains B, Majjaj S, Lallemand F, Durbecq V, Larsimont D, Gonzalez-Angulo AM, Pusztai L, Symmans WF, Bardelli A, et al. 2010 PIK3CA mutations associated with gene signature of low mTORC1 signaling and better outcomes in estrogen receptorpositive breast cancer. PNAS 107 10208-10213. (doi:10.1073/ pnas.0907011107)

Ma CX, Luo J, Naughton M, Ademuyiwa F, Suresh R, Griffith M, Griffith OL, Skidmore ZL, Spies NC, Ramu A, et al. 2015 A phase 1 trial of BKM120 (Buparlisib) in combination with fulvestrant in postmenopausal women with estrogen receptor positive metastatic breast cancer. Clinical Cancer Research 22 1583-1591. (doi:10.1158/1078-0432.ccr-15-1745)
Maira SM, Pecchi S, Huang A, Burger M, Knapp M, Sterker D, Schnell C, Guthy D, Nagel T, Wiesmann M, et al. 2012 Identification and characterization of NVP-BKM120, an orally available pan class I PI3-Kinase inhibitor. Molecular Cancer Therapeutics 11 317-328. (doi:10.1158/1535-7163.MCT-11-0474)

Maycotte P \& Thorburn A 2014 Targeting autophagy in breast cancer. World Journal of Clinical Oncology 5 224-240. (doi:10.5306/wjco.v5. i3.224)

Mayer IA, Abramson VG, Isakoff SJ, Forero A, Balko JM, Kuba MG, Sanders ME, Yap JT, Van den Abbeele AD, Li Y, et al. 2014 Stand up to cancer phase ib study of pan-phosphoinositide-3-kinase inhibitor buparlisib with letrozole in estrogen receptor-positive/human epidermal growth factor receptor 2-negative metastatic breast cancer. Journal of Clinical Oncology 32 1202-1209. (doi:10.1200/ JCO.2013.54.0518)

McDonnell DP, Wardell SE \& Norris JD 2015 Oral selective estrogen receptor downregulators (SERDs), a breakthrough endocrine therapy for breast cancer. Journal of Medicinal Chemistry 58 4883-4887. (doi:10.1021/acs.jmedchem.5b00760)

McGuire WL, Horwitz KB, Pearson OH \& Segaloff A 1977 Current status of estrogen and progesterone receptors in breast cancer. Cancer 39 (6 Supplement) 2934-2947. (doi:10.1002/10970142(197706)39:6<2934::AID-CNCR2820390680>3.0.CO;2-P)

Meric-Bernstam F, Frampton GM, Ferrer-Lozano J, Yelensky R, Pérez-Fidalgo JA, Wang Y, Palmer GA, Ross JS, Miller VA, Su X, et al. 2014 Concordance of genomic alterations between primary and recurrent breast cancer. Molecular Cancer Therapeutics 13 1382-1389. (doi:10.1158/1535-7163.MCT-13-0482)

Miller TW, Hennessy BT, González-Angulo AM, Fox EM, Mills GB, Chen H, Higham C, García-Echeverría C, Shyr Y \& Arteaga CL 2010 Hyperactivation of phosphatidylinositol-3 kinase promotes escape from hormone dependence in estrogen receptor-positive human breast cancer. Journal of Clinical Investigation 120 2406-2413. (doi:10.1172/JCI41680)

Miller TW, Balko JM \& Arteaga CL 2011a Phosphatidylinositol 3-kinase and antiestrogen resistance in breast cancer. Journal of Clinical Oncology 29 4452-4461. (doi:10.1200/JCO.2010.34.4879)

Miller TW, Rexer BN, Garrett JT \& Arteaga CL 2011b Mutations in the phosphatidylinositol 3-kinase pathway: role in tumor progression and therapeutic implications in breast cancer. Breast Cancer Research 13 224. (doi:10.1186/bcr3039)

Morgan D 1997 Cyclin dependent kinases: engines, clocks and microprocessors. Annual Review of Cell and Developmental Biology 13 261-291. (doi:10.1146/annurev.cellbio.13.1.261)

Moynahan ME, Sung P, Chen D, He W, Samoila A, You D, Bhatt T, Patel P, Ringeisen FP, Hortobagyi GN, et al. 2016 Correlation of PIK3CA mutations in cell-free DNA (cfDNA) and efficacy of everolimus (EVE) in metastatic breast cancer: results from BOLERO-2. Journal of Clinical Oncology $\mathbf{3 4}$ (supplement ASCO Meetings Abstract 519).

Munster PN, Paige Hamilton E, Franklin C, Bhansali S, Wan K, Hewes B \& Juric D 2014 Phase lb study of LEE011 and BYL719 in combination with letrozole in estrogen receptor-positive, HER2negative breast cancer (ER+, HER2- BC). Journal of Clinical Oncology 32 (supplement ASCO Meetings Abstract 533).

Murphy CG \& Dickler MN 2015 The role of CDK4/6 inhibition in breast cancer. Oncologist 20 483-490. (doi:10.1634/theoncologist.2014-0443)

NCCN 2016 NCCN breast cancer guidelines. Accessed 3 January 2016. Fort Washington, PA, USA: National Comprehensive Cancer Network. (available at: http://www.nccn.org/professionals/physician gls/f_guidelines.asp\#site)

Ndubaku CO, Heffron TP, Staben ST, Baumgardner M, Blaquiere N, Bradley E, Bull R, Do S, Dotson J, Dudley D, et al. 2013 Discovery of 2-\{3-[2-(1-isopropyl-3-methyl-1H-1,2-4-triazol-5-yl)-5,6dihydrobenzo[f]imidazo[1,2-d][1,4]oxazepin-9-yl]-1H-pyrazol-1-yl\}-2methylpropanamide (GDC-0032): a $\beta$-sparing phosphoinositide 
3-kinase inhibitor with high unbound exposure and robust in vivo antitumor activity. Journal of Medicinal Chemistry 56 4597-4610. (doi:10.1021/jm4003632)

Osborne CK, Pippen J, Jones SE, Parker LM, Ellis M, Come S, Gertler SZ, May JT, Burton G, Dimery I, et al. 2002 Double-blind, randomized trial comparing the efficacy and tolerability of fulvestrant versus anastrozole in postmenopausal women with advanced breast cancer progressing on prior endocrine therapy: results of a North American trial. Journal of Clinical Oncology 20 3386-3395. (doi:10.1200/ JCO.2002.10.058)

Pao W, Miller VA, Politi KA, Riely GJ, Somwar R, Zakowski MF, Kris MG \& Varmus H 2005 Acquired resistance of lung adenocarcinomas to gefitinib or erlotinib is associated with a second mutation in the EGFR kinase domain. PLoS Medicine 2 e73. (doi:10.1371/journal. pmed.0020073)

Pardee AB 1989 G1 events and regulation of cell cycle progression. Science 246 603-608. (doi:10.1126/science.2683075)

Patnaik A, Rosen LS, Tolaney SM, Tolcher AW, Goldman JW, Gandhi L, Papadopoulos KP, Beeram M, Rasco DW, Myrand SP, et al. 2014a Clinical activity of LY2835219, a novel cell cycle inhibitor selective for CDK4 and CDK6, in patients with metastatic breast cancer. Proceedings of the 105th annual meeting of the American Association for Cancer Research; 2014 April 5-9; San Diego, CA, USA. Cancer Research 74 (19 Supplement) abstract CT232. (doi:10.1158/1538-7445.am2014-ct232)

Patnaik A, Rosen LS, Tolaney SM, Tolcher AW, Goldman JW, Gandhi L, Papadopoulos KP, Beeram M, Rasco DW, Myrand SP, et al. 2014b LY2835219, a novel cell cycle inhibitor selective for CDK4/6, in combination with fulvestrant for patients with hormone receptor positive (HR+) metastatic breast cancer. Journal of Clinical Oncology 32 (May 20 Supplement) abstract 534. (available at: http://meeting. ascopubs.org/cgi/content/abstract/32/15_suppl/534)

Piccart M, Hortobagyi GN, Campone M, Pritchard KI, Lebrun F, Ito Y, Noguchi S, Perez A, Rugo HS, Deleu I, et al. 2014 Everolimus plus exemestane for hormone-receptor-positive, human epidermal growth factor receptor-2-negative advanced breast cancer: overall survival results from BOLERO-2. Annals of Oncology 25 2357-2362. (doi:10.1093/annonc/mdu456)

Pike AC, Brzozowski AM \& Walton J 2001 Structural insights into the mode of action of a pure antiestrogen. Structure 9 145-153. (doi:10.1016/S0969-2126(01)00568-8)

Raynaud FI, Eccles SA, Patel S, Alix S, Box G, Chuckowree I, Folkes A, Gowan S, De Haven Brandon A, Di Stefano F, et al. 2009 Biological properties of potent inhibitors of class I phosphatidylinositide 3-kinases: from PI-103 through PI-540, PI-620 to the oral agent GDC-0941. Molecular Cancer Therapeutics 8 1725-1738. (doi:10.1158/1535-7163.MCT-08-1200)

Robertson JF, Nicholson RI \& Bundred NJ 2001 Comparison of the short-term biological effects of 7alpha-[9-(4,4,5,5,5pentafluoropentylsulfinyl)-nonyl] estra-1,3,5, (10)-triene-3,17beta-diol (Faslodex) versus tamoxifen in postmenopausal women with primary breast cancer. Cancer Research 61 6739-6746.

Robertson JF, Llombart-Cussac A, Rolski J, Feltl D, Dewar J, Macpherson E, Lindemann J \& Ellis MJ 2009 Activity of fulvestrant $500 \mathrm{mg}$ versus anastrozole $1 \mathrm{mg}$ as first-line treatment for advanced breast cancer: results from the FIRST study. Journal of Clinical Oncology 27 4530-4535. (doi:10.1200/JCO.2008.21.1136)

Robertson JF, Lindemann JP, Llombart-Cussac A, Rolski J, Feltl D, Dewar J, Emerson L, Dean A \& Ellis MJ 2012 Fulvestrant 500mg versus anastrozole $1 \mathrm{mg}$ for the first-line treatment of advanced breast cancer: follow-up analysis from the randomized 'FIRST' study. Breast Cancer Research and Treatment 136 503-511. (doi:10.1007/s10549-012-2192-4)

Robertson JF, Osborne CK, Howell A, Jones SE, Mauriac L, Ellis M, Kleeberg UR, Come SE, Vergote I, Gertler S, et al. 2003 Fulvestrant versus anastrozole for the treatment of advanced breast carcinoma in postmenopausal women: a prospective combined analysis of two multicenter trials. Cancer 98 229-238. (doi:10.1002/ (ISSN)1097-0142)

Robertson JF, Ferrero JM, Bourgeois H, Kennecke H, de Boer RH, Jacot W, McGreivy J, Suzuki S, Zhu M, McCaffery I, et al. 2013 Ganitumab with either exemestane or fulvestrant for postmenopausal women with advanced, hormone-receptor-positive breast cancer: a randomized, controlled, double-blind, phase 2 trial. Lancet Oncology 14 228-235. (doi:10.1016/S1470-2045(13)70026-3)

Robinson DR, Wu YM, Vats P, Su F, Lonigro RJ, Cao X, Kalyana-Sundaram S, Wang R, Ning Y, Hodges L, et al. 2013 Activating ESR1 mutations in hormone-resistant metastatic breast cancer. Nature Genetics 45 1446-1451. (doi:10.1038/ng.2823)

Saal LH, Holm K, Maurer M, Memeo L, Su T, Wang X, Yu JS, Malmström PO, Mansukhani M, Enoksson J, et al. 2005 PIK3CA mutations correlate with hormone receptors, node metastasis, and ERBB2, and are mutually exclusive with PTEN loss in human breast carcinoma. Cancer Research 65 2554-2559. (doi:10.1158/0008-5472CAN-04-3913)

Sadee W \& Dai Z 2005 Pharmacogenetics/genomics and personalized medicine. Human Molecular Genetics 14 R207-R214. (doi:10.1093/ hmg/ddi261)

Schwartz GK, LoRusso PM, Dickson MA, Randolph SS, Shaik MN, Wilner KD, Courtney R \& O'Dwyer PJ 2011 Phase I study of PD 0332991, a cyclin-dependent kinase inhibitor, administered in 3-week cycles (Schedule 2/1). British Journal of Cancer $\mathbf{1 0 4}$ 1862-1868. (doi:10.1038/bjc.2011.177)

Schwartz S, Wongvipat J, Trigwell CB, Hancox U, Carver BS, Rodrik-Outmezguine V, Will M, Yellen P, de Stanchina E, Baselga J, et al. 2015 Feedback suppression of PI3K $\alpha$ signaling in PTEN-mutated tumors is relieved by selective inhibition of PI3K $\beta$. Cancer Cell 27 109-122. (doi:10.1016/j.ccell.2014.11.008)

Sedlacek H, Czech J, Naik R, Kaur G, Worland P, Losiewicz M, Parker B, Carlson B, Smith A, Senderowicz A, et al. 1996 Flavopiridol (L86 8275; NSC 649890), a new kinase inhibitor for tumor therapy. International Journal of Oncology 9 1143-1168. (doi:10.3892/ ijo.9.6.1143)

Shapiro GI 2006 Cyclin-dependent kinase pathways as targets for cancer treatment. Journal of Clinical Oncology 24 1170-1183. (doi:10.1200/ JCO.2005.03.7689)

Sherr CJ 1995 D-type cyclins. Trends in Biochemical Sciences 20 187-190. (doi:10.1016/S0968-0004(00)89005-2)

Sighoko D, Liu J, Hou N, Gustafson P \& Huo D 2014 Discordance in hormone receptor status among primary, metastatic, and second primary breast cancers: biological difference or misclassification? Oncologist 19 592-601. (doi:10.1634/theoncologist.2013-0427)

Tamborini E, Pricl S, Negri T, Lagonigro MS, Miselli F, Greco A, Gronchi A, Casali PG, Ferrone M, Fermeglia M, et al. 2006 Functional analyses and molecular modeling of two c-Kit mutations responsible for imatinib secondary resistance in GIST patients. Oncogene 25 6140-6146. (doi:10.1038/sj.onc.1209639)

Thangavel C, Dean JL, Ertel A, Knudsen KE, Aldaz CM, Witkiewicz AK, Clarke R \& Knudsen ES 2011 Therapeutically activating RB: reestablishing cell cycle control in endocrine therapy-resistant breast cancer. Endocrine-Related Cancer 18 333-345. (doi:10.1530/ ERC-10-0262)

Toy W, Shen Y, Won H Green B, Sakr RA, Will M, Li Z, Gala K, Fanning S, King TA, et al. 2013 ESR1 ligand-binding domain mutations in hormone-resistant breast cancer. Nature Genetics $\mathbf{4 5}$ 1439-1445. (doi:10.1038/ng.2822)

Turner N, Pearson A, Sharpe R, Lambros M, Geyer F, Lopez-Garcia MA, Natrajan R, Marchio C, Iorns E, Mackay A, et al. 2010 FGFR1 amplification drives endocrine therapy resistance and is a therapeutic target in breast cancer. Cancer Research 70 2085-2094. (doi:10.1158/0008-5472.CAN-09-3746)
() 2016 Society for Endocrinology Printed in Great Britain 
Turner NC, Ro J, André F, Loi S, Verma S, Iwata H, Harbeck N, Loibl S, Huang Bartlett C, Zhang K, et al. 2015 Palbociclib in hormonereceptor-positive advanced breast cancer. New England Journal of Medicine 373 209-219. (doi:10.1056/NEJMoa1505270)

US Food and Drugs Administration 2016 FDA label information for palbociclib. Accessed 16 March 2016. White Oak, MD, USA: US Food and Drugs Administration. (available at: www.accessdata.fda.gov/ drugsatfda_docs/label/2016/207103s002lbl.pdf)

Vanhaesebroeck B, Guillermet-Guibert J, Graupera M \& Bilanges B 2010 The emerging mechanisms of isoform-specific PI3K signalling. Nature Reviews: Molecular Cell Biology 11 329-341. (doi:10.1038/ nrm2882)

van Kruchten M, de Vries EG, Glaudemans AW, van Lanschot MC, van Faassen M, Kema IP, Brown M, Schröder CP, de Vries EF \& Hospers GA 2015 Measuring residual estrogen receptor availability during fulvestrant therapy in patients with metastatic breast cancer. Cancer Discovery 5 72-81. (doi:10.1158/2159-8290.CD-14-0697)

Vora SR, Juric D, Kim N, Mino-Kenudson M, Huynh T, Costa C, Lockerman EL, Pollack SF, Liu M, Li X, et al. 2014 CDK 4/6 inhibitors sensitize PIK3CA mutant breast cancer to PI3K inhibitors. Cancer Cell 26 136-149. (doi:10.1016/j.ccr.2014.05.020)

Wakeling AE, Dukes M \& Bowler J 1991 A potent specific pure antiestrogen with clinical potential. Cancer Research 51 3867-3873.

Wardell SE, Marks JR \& McDonnell DP 2011 The turnover of estrogen receptor $\alpha$ by the selective estrogen receptor degrader (SERD) fulvestrant is a saturable process that is not required for antagonist efficacy. Biochemical Pharmacology 82 122-130. (doi:10.1016/ j.bcp.2011.03.031)

Watts CK, Brady A, Sarcevic B deFazio A, Musgrove EA \& Sutherland RL 1995 Antiestrogen inhibition of cell cycle progression in breast cancer cells in associated with inhibition of cyclin-dependent kinase activity and decreased retinoblastoma protein phosphorylation. Molecular Endocrinology 9 1804-1813. (doi:10.1210/ mend.9.12.8614416)

Wee S, Wiederschain D, Maira SM Loo A, Miller C, deBeaumont R, Stegmeier F, Yao YM \& Lengauer C 2008 PTEN-deficient cancers depend on PIK3CB. PNAS 105 13057-13062. (doi:10.1073/ pnas.0802655105)

Weinberg RA 1995 The retinoblastoma protein and cell cycle control. Cell 81 323-330. (doi:10.1016/0092-8674(95)90385-2)

White E 2012 Deconvoluting the context-dependent role for autophagy in cancer. Nature Reviews: Cancer 12 401-410. (doi:10.1038/nrc3262)

Wolff AC, Lazar AA, Bondarenko I, Garin AM, Brincat S, Chow L, Sun Y, Neskovic-Konstantinovic Z, Guimaraes RC, Fumoleau P, et al. 2013 Randomized phase III placebo-controlled trial of letrozole plus oral temsirolimus as first-line endocrine therapy in postmenopausal women with locally advanced or metastatic breast cancer. Journal of Clinical Oncology 31 195-202. (doi:10.1200/ JCO.2011.38.3331)

Yardley DA, Ismail-Khan RR, Melichar B Lichinitser M, Munster PN, Klein PM, Cruickshank S, Miller KD, Lee MJ \& Trepel JB 2013 Randomized phase II, double-blind, placebo-controlled study of exemestane with or without entinostat in postmenopausal women with locally recurrent or metastatic estrogen receptor-positive breast cancer progressing on treatment with a nonsteroidal aromatase inhibitor. Journal of Clinical Oncology 31 2128-2135. (doi:10.1200/ JCO.2012.43.7251)

Zhang QX, Borg A, Wolf DM, Oesterreich S \& Fuqua SA 1997 An estrogen receptor mutant with strong hormone independent activity from a metastatic breast cancer. Cancer Research 57 1244-1249.

Received in final form 15 June 2016

Accepted 24 June 2016

Accepted Preprint published online 24 June 2016
(C) 2016 Society for Endocrinology Printed in Great Britain
Published by Bioscientifica Ltd. 